\title{
Deglutition Syncope Due to Exaggerated Vagal Reflex
}

\author{
Xuanzhen Piao $^{1}$, Michael J. Chaney ${ }^{1}$, Grace W. Ying ${ }^{2}$, Artem Sharko ${ }^{2}$, Shirly Samuel ${ }^{2}$ \\ 1. Internal Medicine, Chicago Medical School Rosalind Franklin University of Medicine and Science, North Chicago, \\ USA 2. Internal Medicine, Chicago Medical School Internal Medicine Residency Program at Northwestern Medicine \\ McHenry Hospital, McHenry, USA
}

Corresponding author: Grace W. Ying, grace.ying@rosalindfranklin.edu

\begin{abstract}
Swallow or deglutition syncope is an uncommon cause of syncope associated with bradyarrhythmia and hypotension during food swallowing. Early recognition of this condition is imperative but challenging. We report a case of a 60-year-old female who presented with a complaint of intermittent lightheadedness after swallowing food. An episode of presyncope was observed and a reduced pulse rate from baseline was noted when she was instructed to eat a candy bar in the clinic. Further workup revealed normal inoffice electrocardiogram, bilateral carotid ultrasound, transthoracic echocardiogram, and videofluoroscopic swallow study. Our goal in presenting this case is to raise awareness of the condition in medical literature
\end{abstract} and provide a good understanding of its clinical manifestation to prevent life-threatening events.

Review began 06/11/2021 Review ended 06/28/2021 Published 06/28/2021

(๑) Copyright 2021 Piao et al. This is an open access article distributed under the terms of the Creative Commons Attribution License CC-BY 4.0., which permits unrestricted use, distribution, and reproduction in any medium, provided the original author and source are credited.
Categories: Internal Medicine, Radiology, Gastroenterology

Keywords: swallow syncope, deglutition syncope, bradyarrhythmia, vagal reflex, pacemaker, unexplained syncope

\section{Introduction}

Swallow or deglutition syncope (DS) is an extremely rare type of neural-mediated reflex syncopal syndrome associated with bradyarrhythmia and hypotension in relation to food ingestion [1]. Since the first reported case in 1793 , there have been only about 100 cases recorded in the literature to date [2-4]. These patients usually present with either presyncopal symptoms or evident syncope [3]. DS has been described to be associated with various esophageal disorders such as esophageal spasm, stricture, achalasia, hiatal hernia, and esophageal cancer [4-7]. In addition, about $15 \%$ of reported cases on DS were associated with cardiac diseases and approximately $39 \%$ of cases had unknown etiologies [8,9]. DS has also been reported in patients without underlying laryngopharyngeal, esophageal or cardiac conditions [10-12]. Recognition of this syndrome is often challenging due to overlapping symptoms with other medical conditions and low case volume. In this case report, we present a patient with swallow syncope who had Schatzki's ring status post repair two years prior to presentation.

\section{Case Presentation}

The patient is a 60-year-old female with a past medical history of chronic gastroesophageal reflux disease, esophageal spasm, Schatzki's ring status post repair two years prior to presentation, asthma, and mild mitral valve prolapse. She presented to the clinic with a complaint of reproducible episodes of lightheadedness immediately after swallowing food for the past four months with each episode lasting 10-60 seconds. She stated that swallowing any hard solid food could trigger these episodes, which almost always resolved spontaneously except for a few times where she was close to passing out. She denied any history of syncope, seizure, stroke, transient ischemic attack, myocardial infarction, cardiac arrhythmia, pulmonary embolism, orthostatic hypotension, ataxia, or vertigo. In regard to the review of symptoms, she denied fever, unintentional weight loss, headache, visual disturbance, neck pain, chest pain, shortness of breath, choking sensation, dysphagia, odynophagia, dyspepsia, nausea, vomiting, abdominal pain, or anxiety. She had appropriate fluid intake and denied any recent illness, head trauma, medication change, or dietary change. Her home medications included pantoprazole and an albuterol inhaler. She denied using tobacco or recreational drugs but endorsed drinking 3-5 servings of wine or beer per week.

On presentation, she had a blood pressure of 126/88 $\mathrm{mmHg}$, heart rate 97 beats per minute, temperature $98.1^{\circ} \mathrm{F}$, respiratory rate 14 breaths per minute, and oxygen saturation of $99 \%$ on room air. The physical exam was unremarkable except for a mitral valve click that was heard over the left sternal border. The initial lab work including complete blood count and the comprehensive metabolic panel was unremarkable. During the initial visit, an episode of presyncope lasting about 10-15 seconds was observed and a reduced pulse rate from baseline was noted when the patient was instructed to eat a candy bar. She reported an intense feeling of lightheadedness but recovered spontaneously without confusion. She was told to continue to monitor her symptoms and a cardiology referral was given for further evaluation. Subsequent diagnostic workup revealed normal in-office electrocardiogram (EKG), bilateral carotid ultrasound, transthoracic echocardiogram (TTE) (Figure 1), and videofluoroscopic swallow study (VFSS) (Figure 2). The patient reported of having mild lightheadedness with swallowing a larger bolus of food during the VFSS, but there was no evidence of 


\section{Cureus}

esophageal dysmotility or change in bolus drive, direction or residue. At home, she continued to experience lightheadedness with swallowing, but not to an extent of affecting her quality of life. Diet modification, symptom monitoring, and fall precaution were discussed and recommended to the patient. If symptoms were to worsen, the patient was instructed to return for a 24-hour ambulatory EKG recording.

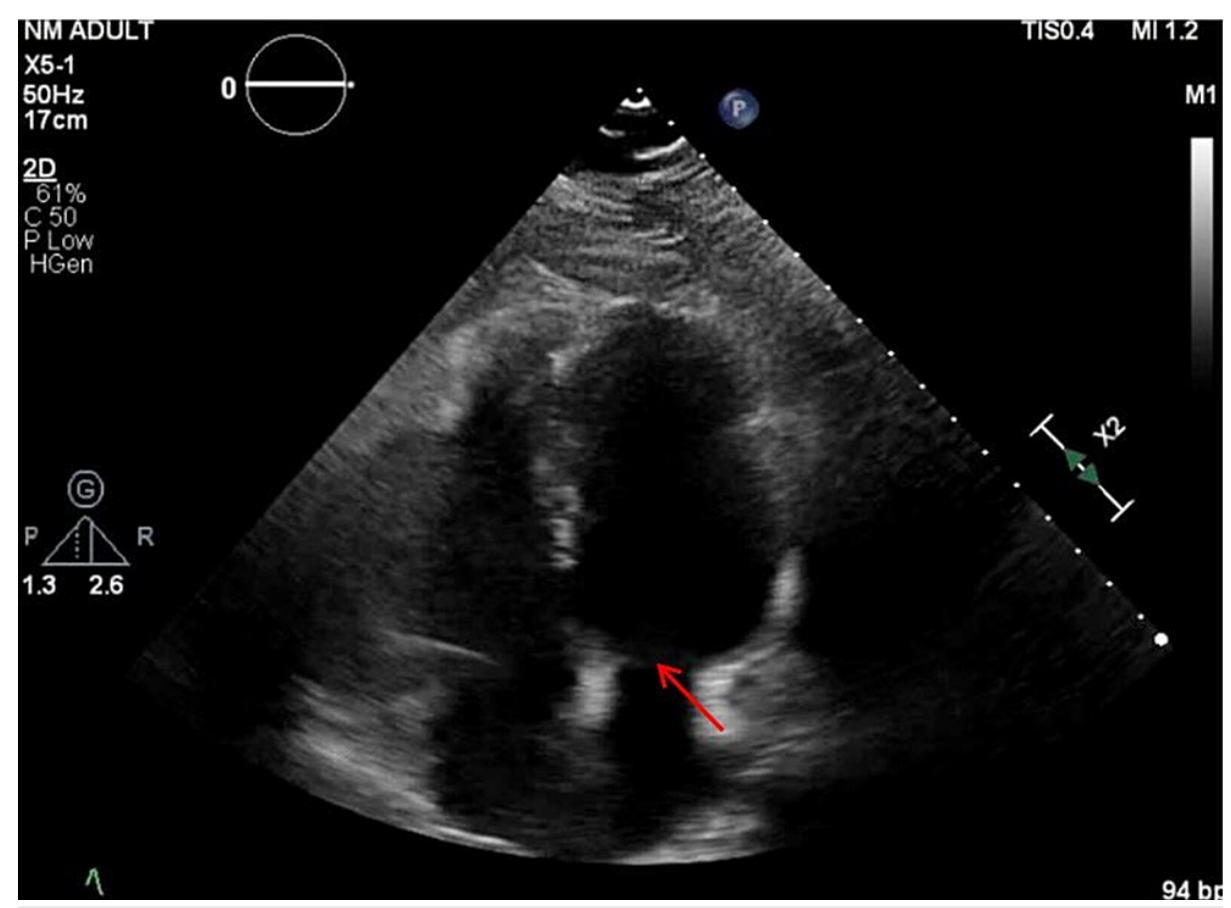

FIGURE 1: Two-dimensional TTE with Doppler in four-chamber view showing normal structure of the heart. There is no evidence of left ventricular hypertrophy. The left ventricular systolic function is normal with an estimated ejection fraction of $60 \%-65 \%$. The trivial to mild mitral valve prolapse (arrow) remains stable compared to prior study.

TTE - transthoracic echocardiogram 


\section{Cureus}

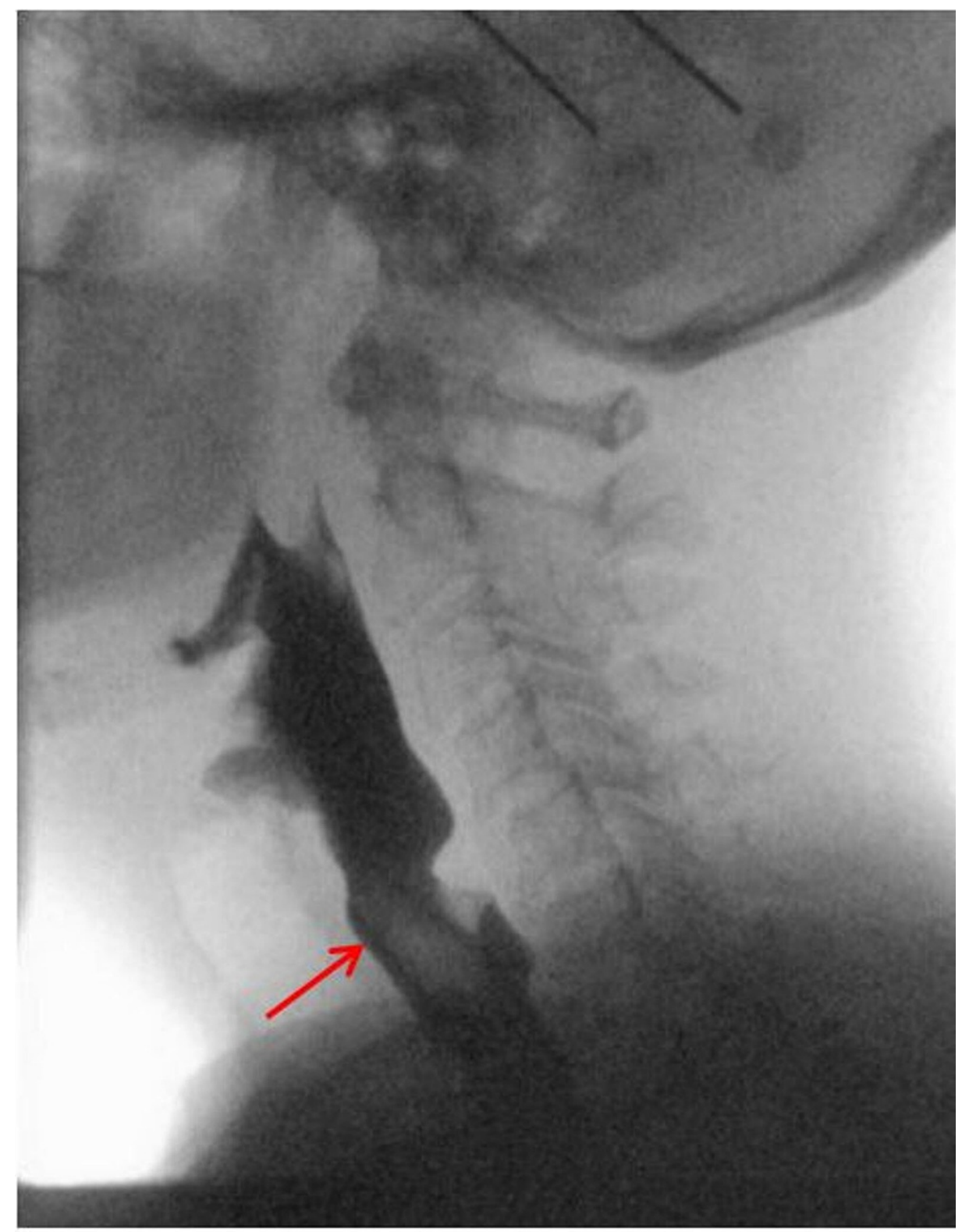

FIGURE 2: VFSS assessed the oral, pharyngeal, and esophageal phases of swallow. The figure shows honey-thick material coating the esophagus (arrow) demonstrating normal appearance without stricture or dysmotility.

VFSS - videofluoroscopic swallow study

DS is often found in older adults, with a mean reported age of 57.5 years at the time of initial presentation [13]. The exact mechanism of DS remains unknown. A few pathophysiological explanations have been discussed in the literature. In general, it is postulated that DS is caused by an exaggerated vagal reflex or stimulation initiated by the process of swallowing that results in temporary suppression of cardiac conduction. During swallow, the mechanoreceptors in the esophagus are being stretched and this process sends afferent impulses to the medulla oblongata via the esophageal plexus [14]. The efferent signals are then mediated by the vagal nerves leading to temporary bradyarrhythmia by innervating the sinoatrial and atrioventricular nodes [9]. The parasympathetic response can also result in hypotension secondary to peripheral vasodilation [15]. When it comes to diagnosing DS, it is essential to rule out any esophageal disorders and cardiac diseases beforehand [9]. The diagnosis of DS involves careful history taking and recognition of presyncopal events or syncope triggered by the process of swallowing (provocative test) [13]. It can be further supported by sinus pause on EKG or reduced pulse rate from the baseline during an episode [13], as shown in our case. 
Before initial treatment, it is essential to identify and avoid the triggers for the vagal response. Discontinuation of medications that suppress cardiac conduction, such as beta-blockers, is considered the mainstay of therapy [4]. Furthermore, anticholinergic medications and sympathomimetic agents such as atropine have been used in the past to prevent bradyarrhythmia in patients with DS. However, the efficacy of these medications has not been well studied and side effects also limit their use [9]. According to current literature, the definitive management of DS is the insertion of a permanent pacemaker in patients with refractory symptoms despite avoiding triggers, withdrawal from atrioventricular nodal blocking medications, and the addition of sympathomimetic agents [9]. Our patient presented with relatively mild symptoms; therefore, the management started with diet modification and avoidance of dry or coarse food such as tough meats. She remained compliant with these changes as they have helped to prevent symptoms.

\section{Conclusions}

DS is a rare cause of syncope with limited cases in the literature and should be considered part of the diagnostic workup in unexplained syncope. It is imperative to rule out esophageal disorders and cardiac disease before making the diagnosis of DS. Given that patients with DS can develop life-threatening bradyarrhythmia and that it is a difficult condition to diagnose, a better understanding of disease manifestation can help prevent delayed treatment.

\section{Additional Information}

\section{Disclosures}

Human subjects: Consent was obtained or waived by all participants in this study. Conflicts of interest: In compliance with the ICMJE uniform disclosure form, all authors declare the following: Payment/services info: All authors have declared that no financial support was received from any organization for the submitted work. Financial relationships: All authors have declared that they have no financial relationships at present or within the previous three years with any organizations that might have an interest in the submitted work. Other relationships: All authors have declared that there are no other relationships or activities that could appear to have influenced the submitted work.

\section{References}

1. Parry SW, Tan MP: An approach to the evaluation and management of syncope in adults . BMJ. 2010, 340:c880. 10.1136/bmj.c880

2. Garg S, Girotra M, Glasser S, Dutta SK: Swallow syncope: clinical presentation, diagnostic criteria, and therapeutic options. Saudi J Gastroenterol. 2014, 20:207-11. 10.4103/1319-3767.136932

3. Bhogal S, Sethi P, Taha Y, et al.: Deglutition syncope: two case reports attributed to vagal hyperactivity . Case Rep Cardiol. 2017, 2017:2145678. 10.1155/2017/2145678

4. Omi W, Murata Y, Yaegashi T, Inomata J, Fujioka M, Muramoto S: Swallow syncope, a case report and review of the literature. Cardiology. 2006, 105:75-9. 10.1159/000089543

5. Waddington JK, Matthews HR, Evans CC, Ward DW: Letter: carcinoma of the oesophagus with "swallow syncope". Br Med J. 1975, 3:232. 10.1136/bmj.3.5977.232-a

6. Kopald HH, Roth HP, Fleshler B, Pritchard WH: Vagovagal syncope; report of a case associated with diffuse esophageal spasm. N Engl J Med. 1964, 271:1238-41. 10.1056/NEJM196412102712404

7. Tolman KG, Ashworth WD: Syncope induced by dysphagia. Correction by esophageal dilatation . Am J Dig Dis. 1971, 16:1026-31. 10.1007/BF02235016

8. Ragaza EP, Rectra EH, Pardi MT: Intermittent complete heart block associated with swallowing as a complication of acute myocardial infarction. Am Heart J. 1970, 79:396-400. 10.1016/0002-8703(70)90427-8

9. Mitra S, Ludka T, Rezkalla SH, Sharma PP, Luo J: Swallow syncope: a case report and review of the literature. Clin Med Res. 2011, 9:125-9. 10.3121/cmr.2010.969

10. Deguchi K, Mathias CJ: Continuous haemodynamic monitoring in an unusual case of swallow induced syncope. J Neurol Neurosurg Psychiatry. 1999, 67:220-2. 10.1136/jnnp.67.2.220

11. Farb A, Valenti SA: Swallow syncope. Md Med J. 1999, 48:151-4.

12. Kakuchi H, Sato N, Kawamura Y: Swallow syncope associated with complete atrioventricular block and vasovagal syncope. Heart. 2000, 83:702-4. 10.1136/heart.83.6.702

13. Siew KSW, Tan MP, Hilmi IN, Loch A: Swallow syncope: a case report and review of literature. BMC Cardiovasc Disord. 2019, 19:191. 10.1186/s12872-019-1174-4

14. Kang KH, Cho WH, Kim MC, Chang HJ, Chung JI, Won DJ: Cases of swallow syncope induced by the activation of mechanorecepters in the lower esophagus. Korean J Intern Med. 2005, 20:68-71. 10.3904/kjim.2005.20.1.68

15. Patel N, Ibrahim S, Shah J, Orellana-Barrios MA, Paterick TE, Tajik AJ: Deglutition syncope. Proc (Bayl Univ Med Cent). 2017, 30:293-4. 10.1080/08998280.2017.11929619 